Finance and Economics Discussion Series Divisions of Research \& Statistics and Monetary Affairs Federal Reserve Board, Washington, D.C.

\title{
Requirements and Prospects for a New Time to Payoff Disclosure for Open End Credit Under Truth in Lending
}

\section{Thomas A. Durkin}

2006-34

NOTE: Staff working papers in the Finance and Economics Discussion Series (FEDS) are preliminary materials circulated to stimulate discussion and critical comment. The analysis and conclusions set forth are those of the authors and do not indicate concurrence by other members of the research staff or the Board of Governors. References in publications to the Finance and Economics Discussion Series (other than acknowledgement) should be cleared with the author(s) to protect the tentative character

of these papers. 


\section{Requirements and Prospects for a New Time to Payoff Disclosure for Open End Credit Under Truth in Lending}

Thomas A. Durkin*

July 2006

* Senior Economist, Board of Governors of the Federal Reserve System

Staff working papers are preliminary materials circulated to stimulate discussion and critical comment. The analysis and conclusions set forth are those of the authors and do not indicate concurrence by other members of the research staff or the Board of Governors. References in other places should be cleared with the authors to protect the tentative character of these papers. 


\section{ABSTRACT}

The Bankruptcy Abuse Prevention and Consumer Protection Act of 2005 (Public Law 109-8, April 2005) made significant changes to procedures for managing consumer bankruptcy petitions, but it also included amendments to the Truth in Lending Act. Notable among the Truth in Lending changes is a section providing for new disclosures on the length of time it will take consumers to repay open end credit accounts in full if they make only the minimum required payments. This paper explores the range of assumptions necessary for the calculations underlying the new required disclosures, examines the sensitivity of the disclosures to variations in the assumptions, and explores the potential for inaccuracy in the required disclosures based upon consumers' use of their open end credit accounts. For the latter exploration, the paper examines consumer survey evidence and employs a large longitudinal sample of credit card accounts to measure how often consumers' actual patterns of use of their credit card accounts match the assumptions of the new disclosure. 
Requirements and Prospects for a New Time to Payoff Disclosure for Open End Credit Under Truth in Lending

The Bankruptcy Abuse Prevention and Consumer Protection Act of 2005 requires creditors to provide to consumers on the front page of all billing statements for open end credit accounts a warning notice that making minimum payments increases interest and time to repay, along with a designated example. The necessary statement must also give a telephone number that the consumer may call to receive an "estimate" of the number of months to repay an outstanding balance if the consumer makes only the minimum required payments. The law permits an exception from some aspects of the new mandates if the creditor is willing to provide the "actual" number of months to payoff to those who call rather than an "estimate." In this case, the example is not required and the warning notice may be anywhere on the billing statement with a telephone number the consumer may call for "further information."

In either situation, the act requires the Federal Reserve Board to provide creditors with methodology and guidance for preparing the new disclosures. This obligates the Board to define the terms and to designate the proper calculating methods for both the "estimate" and "actual" months to payoff. Creditors can then decide whether to provide the "estimate" or the "actual" months based on their individual evaluations of the importance of using the first page of their billing notices for this sort of warning and example instead of other information, together with their assessments of the costs and burdens imposed in providing the disclosure alternatives.

This paper examines the assumptions necessary for calculations underlying the "estimate" of and "actual" number of months to payoff, uses simulations to illustrate the sensitivity of the disclosures to the underlying assumptions, and examines the degree to which the assumptions correspond to the way that consumers actually use credit card accounts, the most common form of open end credit. For the latter discussion, the paper employs consumer survey evidence and data from a large sample of credit 
card accounts at major card issuing banking institutions to explore how often actual account use behavior may or may not render the required disclosures rapidly obsolete.

\section{Background}

Section 1301 of the Bankruptcy Abuse Prevention and Consumer Protection Act of 2005 (Public Law 109-8) amends the Truth in Lending Act (15 USC 1601 et seq.) to require three new disclosures on the front of all billing statements for open end consumer and mortgage credit. 'This amendment also mandates procedures for providing to requesting consumers by telephone an "estimate" of the number of months it would take them to pay off their balances if making only the minimum mandatory payment. Unlike the latter disclosure given only to those who call, the three disclosures required on the billing statement are not specific to individual accounts and may be preprinted:

1) a warning notice that making only minimum payments permitted under the credit contract will increase interest and the time to repay;

2) a required simple example of time to repay a hypothetical account of a certain size with a 17 per cent annual percentage rate and a "typical" payment amount specified in the statute and dependent on other aspects of the example; and

3) a telephone number the consumer may call "for an estimate of the number of months it would take to repay your balance, making only minimum payments..." (paragraph 1301a(11)(A)).

This section of the act also provides for an exemption from requiring the otherwise mandatory warning notice, the example, and the telephone number on the first page of the billing notice for those institutions willing to provide by telephone the

\footnotetext{
${ }^{1}$ Open end credit is credit where the size and timing of the credit advances and repayment amounts are at the discretion of the consumer as long as the credit advances do not exceed some prearranged credit line and the payments at least equal some contractual minimum payment. Credit card accounts are the most common form of open end consumer credit, and home equity credit lines are the most common form of open end mortgage credit.
} 
"actual" number of months to payoff." In this situation the creditor may place the warning notice anywhere in the statement, may omit the example, and must indicate a toll free telephone number the account holder can call "for more information" about the time it takes to repay (paragraphs 1301a(11)(J) and (K)).

To supply guidance to those receiving such telephone calls, the Federal Reserve Board is to "establish a detailed table illustrating the approximate number of months that it would take to repay an outstanding balance if a consumer pays only the required minimum monthly payments ... which table shall clearly present standardized information to be used to disclose the information required to be disclosed..." The act states that the Federal Reserve is to "establish the table required ... by assuming --

i) a significant number of different annual percentage rates;

ii) a significant number of different account balances;

iii) a significant number of different payment amounts; and

iv) that only minimum monthly payments are made and no additional extensions of credit are obtained" (paragraph $1301 \mathrm{a}(11)(\mathrm{H}))$.

Further, the Federal Reserve is to "promulgate regulations that provide instructional guidance regarding the manner in which the information contained in the table established ... should be used in responding to the request of an obligor for any information required to be disclosed...." (paragraph $1301 \mathrm{a}(11)(\mathrm{H}))$. On this point the act adds, "A person that receives a request for information ... from an obligor ... shall disclose in response to such request only the information set forth in the table promulgated by the Board..." (paragraph $1301 a(11)(F))$.

${ }^{2}$ This exception is not available to creditors regulated by the Federal Trade Commission, primarily retail stores and finance companies (see paragraph $1301 \mathrm{a}(11)(\mathrm{J}))$. 
Thus, the Federal Reserve is to prepare both the methodology for calculating the estimate of number of months to payoff and regulatory guidance on how to use the methodology.

The Formula and the Information Required

Underlying any tabular presentation of mathematical results there is, of course, a formula or relationship that produces the results. Because of the nature of modern open end credit accounts, the underlying formula for calculating the time to payoff for even a common bank credit card plan with relatively simple terms can be quite formidable. As the complexity of the terms escalates, so does the complexity of their interrelationships.

To illustrate, an account with three sub balances and three corresponding periodic interest rates (for purchases, cash advances, and special promotional convenience checks, all of which are common on consumers' accounts) the relationship is quite complicated algebraically, even with simplified expression of other aspects of the terms. For example, representing a system with monthly compounding always at the end of the month, no grace period, a constant fixed payment of the same percentage of the outstanding balance month after month (with an absolute minimum), no further additions to the account balance after the starting balance except interest, and never a default or late payment would require more than twenty equations, including definitions. Much of the complexity of the system arises from the need to adopt payment allocation rules when there are multiple sub balances, even with a straightforward payment allocation approach like a revenue maximizing assumption that assigns the payments received fully to the sub balance with the lowest interest rate until it is completely repaid. Then payments can be allocated in full to the balance at the next higher rate and so on until the entire amount is paid in full. Much more complicated systems are also possible. 
Solution would also require specification of information on the three beginning balances and the respective interest rates at which these balances compound, the payment percentage (say 2\% or some other percentage), the absolute minimum payment (say $\$ 20$, $\$ 10$, or some other amount), plus another equation which indicates what happens when the calculated required monthly payment falls below the absolute contractual minimum. Normally, the required payment would stop declining at this point and would remain at the contractual minimum.

Fortunately, the nature of open end credit lends itself to iterative solution of a problem of this nature, as might be undertaken through a computer program. An iterative computer solution also easily permits employment of a variety of alternative assumptions that then can produce corresponding sets of solutions, one for each variation in an underlying assumption. Even so, it is necessary to outline a group of opening conditions and assumptions necessary to make the problem tractable even with a computer.

Specifically, each solution for the number of months to payoff of an open end credit account using an iterative approach requires the following information:

1. Current balance outstanding;

2. Compounding rate (interest rate; if there are multiple rates each applicable to a different sub balance, then each rate and sub balance would be necessary);

3. Future additions to the balance (or sub balance) and future subtractions other than the amount of the required minimum payment ;

4. Compounding rule (in open end credit this is usually referred to as the balance calculation or computation method);

5. Contractual rules for calculating the consumer's required minimum payment (including the rules for absolute minimum dollar amount of payment, for minimum finance charges, for residual interest in the final month, etc.);

6. Rules to account for anomalous cases (skip payment plans, temporary negative amortization, workout arrangements, etc.). 
It is apparent from the statute that Congress understood how the nature of open end credit poses difficulties for calculating time to payoff. Some of the information necessary for this calculation varies widely among consumers' accounts (specifically, balance outstanding, interest rate, and required and actual payment amounts). Congressional contemplation of such variations presumably is what led to providing that the Federal Reserve's table must contain "significant" numbers of account balances, interest rates, and payment amounts.

\section{Statutory Assumptions and Examples}

As beginning guidance for preparing the necessary table, the Congress explicitly provided two assumptions and implicitly outlined some others in the statute. The explicit Congressional assumptions are in the sections quoted above and can be referred to as the "statutory assumptions":

1. Only minimum monthly payments are made;

2. No additional extensions of credit are obtained.

Taken together, these two assumptions provide a mandate for item number three in the list of requirements indicated above as necessary for solving the system: future additions and subtractions from the account balance other than required minimum payment are zero. Whether or not these assumptions describe consumers' actual behavior very often, they do resolve this particular mathematical issue.

Beyond these explicit statutory assumptions, close review of the examples required by the statute provides elaboration and some further assumptions:

A. There is no grace period, in other words, the account is already in a revolving condition. If there were a grace period (meaning no finance charge the first month), the example in the statute that pays off in 88 months would pay off instead in 86 months. The assumption of previous revolving condition seems quite realistic anyway, in that accounts providing only the 
minimum required payment for the next seven years are probably already in a revolving situation.

B. The previous balance method is used for balance calculation. If the more common average daily balance method were used for balance calculation in the statutory example that otherwise pays off in 88 months, there would still be a few dollars due in month 89. This is a relatively small difference in outcome, but indicative that the statutory example employs the previous balance method of compounding.

C. The minimum payment percentage or rule can vary among accounts; it is 2 percent in one statutory example, and 5 percent in the other.

D. There is an absolute minimum payment expressed in monetary units rather than as a percentage. This is necessary for producing a finite outcome; it is $\$ 20$ in one statutory example and $\$ 15$ in the other.

E. There is no residual finance charge after the final month in a series of payments, that is, the final payment pays the account in full. This assumption is also necessary for solving the statutory examples at the indicated terms, but also more generally for there to be a finite solution.

Taken together, these five further assumptions seem inherent in the statutory examples and suggest some approaches to narrowing the range of the mathematical requirements listed above as needed for solving with an iterative approach the equation system providing the time to payoff.

\section{Calculation Rules For Solution Examples}

With these assumptions based upon the statute, and by providing reasonable assumptions for other formula components as needed, it is possible to generate some examples of the new required disclosures using selected specifications of possible initial conditions. The following list provides an example of a set of assumptions and initial conditions necessary for the underlying calculations. 
1) The formula. As noted, the statute provides that the Federal Reserve is to establish a "table" for use in disclosing estimates of months to payoff for open end credit accounts. The table is to allow for a "significant number" of different account balances, annual percentage rates, and payment amounts. Because behind any such table there is a calculating rule or formula, it seems the underlying formula is a potential substitute for a table. It certainly permits a "significant" number of balances, annual percentage rates, and payment amounts by allowing use of any observations on these measures. The specific observations of balances, rates, and payments entered into the formula then depend on the information system that provides them and not upon an artificial tabular approach that limits them into ranges.

The author has prepared and will make available on request an appendix to this paper in the form of a computer program in the SAS programming language to calculate the number of months to payoff of an open end credit account. As a base case, it adopts the explicit and implicit statutory assumptions indicated above and further elaborated below, and it requires further input only of balances and rates to provide consistent solutions on this basis. As written, it allows for the possibility of up to three balance components compounding at three different annual percentage rates, but it is easily expandable to more balances and rates as needed. For comparison, the program also contains substitute assumptions in some areas, discussed next. Sensitivity of the base case solution to the substitute assumptions is indicated in tables that follow.

2) Statutory assumptions. The program calculates the months to payoff based on an account where there are no further additions to the account balance or any subtractions except the required minimum balance (the explicit statutory assumptions). There are no convenient alternative specifications for this condition, both because of its statutory nature but also because allowing alternatives would lead to a virtually limitless list of contingent possibilities. 
3) Balances and rates. System solution requires an input of balances and rates. These amounts vary among consumers' accounts and there is no correct selection or combination for use as illustrations, but simulation solutions can show the sensitivity of estimates of time to payoff to various balances and compounding rates, both individually and together. Source of the information used in actual disclosures to consumers might become a differentiating factor between an "estimate" and provision of "actual" number of months to payoff.

In the solution examples that follow, balances of $\$ 1000$, $\$ 3000$, and $\$ 7000$ are chosen for illustrative purposes, along with interest rates of 17 percent, 12 percent, and 8.99 percent. These balances and rates represent a fairly standard set of terms available in the marketplace for credit card accounts. Balances of $\$ 1000, \$ 3000$, and $\$ 7000$ represent a possible range of revolving balances from relatively small to relatively large. Likewise, annual percentage rates of 17 percent, 12 percent, and 8.99 percent are rates that can be found in the marketplace, ranging from relatively high down to relatively low.

4) Compounding/balance computation method. The base assumption about compounding arises from the statutory example. The example uses the previous balance method of compounding in which the finance charge is calculated at the end of a month dependent upon the ending balance that month after deduction of the payment received. An alternative specification is the more common average daily balance approach in which finance charges accrue and are compounded daily. Use of an average daily balance calculation also requires some further timing assumptions, however.

First, use of an average daily balance method for the new disclosures must make some assumption about the number of days in each given month to which it applies. The easiest approach is to assume that all months are the same length (30.41667 days) to account for the full 365 days in a year, ignoring leap year). Since the required disclosure is number of months and not number of days to payoff, it does not matter that the months each 
include a fractional day. In this way the calculation accounts for 365 days over twelve months without requiring specification of a starting month (and ignoring any leap year effects).

Second, calculations using the average daily balance approach must make some assumption about dates of crediting the payments. One possibility is to assume crediting on the last day of the billing cycle, which is the approach in the simulations that follow. Then a finance charge on the remaining balance accrues and compounds daily until the last day of the next period. An alternative is to assume the payment arrives uniformly on some other day (say, day 25 of the billing cycle or at mid month) or that payments arrive on random days. The latter is likely unreasonable, since most people probably pay their credit card bill sometime toward the end of a billing cycle. Any timing choice for illustrative purposes is arbitrary, but a better choice than payment on the last day is not immediately obvious, and so this assumption is chosen for the base set. It is easy enough to compare results to the case of payments received uniformly at mid month or some other time.

The solution examples that follow employ both the ending balance and average daily balance alternative compounding approaches. The average daily balance solutions assume years of 12 months of 30.41667 days and that payments are credited at the end of the billing cycle before the bill is mailed.

5) Minimum payment rule. Each creditor has its own minimum periodic payment policy, which may vary by balance, rate, and other factors. Nonetheless, because the Federal Reserve cannot construct its table on the approach of only one company, specification of a minimum payment requirement calls for a more general approach. The statute contains one obvious approach: a percentage of outstanding balance. The statutory example for banking institutions is 2 percent of the amount outstanding or $\$ 20$, whichever is greater, or the full account balance if less than $\$ 20$.

Otherwise, there is no specific industry standard for minimum payments, but in recent months the office of the 
Comptroller of the Currency (OCC) has strongly suggested that national banks that are issuers of credit cards use a formula approximating the one preferred by that agency. The formula prevents negative amortization by requiring that minimum payments never be less than the sum of all finance charges and fees plus one percent of the outstanding balance. Because this approach appears to be developing into an industry standard de facto, the OCC approach is an alternative to the 2 percent approach. Other similar approaches are also possible, such as payment of all finance charges and fees plus 2 percent, 3 percent, or some other percentage of the amount outstanding.

The solution examples that follow use four methods for determining the minimum payment. The first is the statutory example of 2 percent of the balance outstanding or $\$ 20$, whichever is greater, or the full balance if less than $\$ 20$. The second is the one referred to here as the "OCC approach" consisting of all finance charges plus 1 percent of the outstanding balance or $\$ 20$, whichever is greater, or the full account balance if less than $\$ 20$.

A second set of examples substitutes two other sets of minimum payment rules, but otherwise keeps the rest of the calculating assumptions the same. Neither of these substitute minimum payment rules is common in the marketplace, or even is used by any particular financial institution. They are chosen because each approximately doubles the minimum payment required by the more common rules. They are: A) a variant of the 2 percent approach but requiring payment of 4 percent of the outstanding balance or $\$ 20$, whichever is greater, or the full account balance if less than $\$ 20$, and B) a variant of the OCC approach in which the required minimum payment equals all accrued finance charges plus 3 percent of the outstanding balance or $\$ 20$, whichever is greater, or the full account balance if less than $\$ 20$.

6) Revolving condition (no grace period). The initial conditions assume there is no grace period before accrual of a finance charge, and the last payment pays the account in full with no residual finance charge. The obvious alternative 
assumption is a one month grace period, in other words finance charges only begin to accrue in the second month of the payment sequence. Because it seems unreasonable that calculations assuming that minimum payments are made for many months or even decades begin with an account not yet in a revolving condition and due a one month grace period, the base set of conditions assumes preexisting revolving condition.

7) No special situation. No specific rule for a special situation like a skip payment plan, default interest rate, etc. applies.

\section{Solution Examples}

The solution simulations show that an "estimate" of time to payoff is sensitive to each of the underlying calculating assumptions. In particular, the simulation solutions show that changes in outstanding balances, interest rates, and rule for minimum payment size each influence estimated time to payoff sharply.

In contrast, both sets of solutions show that choice between the previous balance and average daily balance compounding methods has very little impact on estimated time to payoff, given the balance size, interest rate, and minimum payment size rule. The compounding method choice changes the estimated time by more than one month in only two examples in the table. Both of these instances occur when the initial balance is large, the rate is high, and the account holder makes only the minimum required payment for decades, not a likely combination.

The simulations demonstrate that the basic order of magnitude of the required minimum payment percentage (say 2 percent versus 4 percent) has a substantial impact on time to payoff (compare Part 1 of Table 1 to Part 3 of the table). But after this important choice, the impact of changing the payment calculating methodology usually is not dramatic (compare Part 1 of the table to Part 2). Notably, adopting a straight percentageof-balance calculating rule versus an alternative occ-type rule 
but requiring approximately the same size payment has substantive impact only at higher balances and rates together with smaller required payment percentages. The impact of alternative payment calculating rules is greater than choice of balance computation method, but much less than the effect of balances, rates, and size of the minimum payment percentage itself.

The table also demonstrates that the ocC-type rule results in shorter time to payoff than the comparable straight percentage rule at annual percentage rates higher than 12 percent and longer times to payoff at rates below 12 percent. Obvious upon reflection, this occurs because at rates higher than 12 percent, the accrued finance charges are more than another percentage point of balance monthly. This produces a larger payment under the OCC approach than under a corresponding straight percentage rule at interest rates above 12 percent. At annual percentage rates below 12 percent, however, the calculated payment under the ocC-type approach is smaller than under the straight percentage of balance approach and, therefore, the calculated time to payoff is longer than under the percentage rule.

\section{The "Estimate" Disclosure}

The simulations show that there can be substantial variation in estimates of time to payoff of open end credit accounts depending on the calculating assumptions, which suggests the difficulty for the Federal Reserve Board in making regulatory choices concerning required definitions and methodology that preserves a reasonable degree of accuracy in the calculation without producing excessive regulatory burden. ${ }^{3}$ Satisfying both goals simultaneously is difficult because of the variability among consumers' accounts. Even if the Board decides that a short list of choices of allowable balance computation/compounding

${ }^{3}$ The discussion that follows is intended for use only in analyzing and illustrating various aspects of the issues involved, consistent with the goals of these working papers, and does not purport to be or represent the Federal Reserve's legal or regulatory analysis of these matters. 
rules and minimum payment size rules is acceptable since choices in this area do not alter the outcome greatly, there remains the issue of sources of information on balances and rates on consumers' accounts, the most important causes of variation in time to payoff.

1) Sources of information on rates and balances. The only sources of information on balances or rates are the accounting systems of account issuers and the consumers who call asking for estimated time to payoff. Requiring use of the former may be more burdensome than relying on information from calling consumers due to the necessity of potentially costly system changes. Perhaps more important, this alternative is not even available in many cases under the structure of the law, which becomes problematic if there is to be consistency in methodology. Customers of small banks and credit unions, for example, are not to call the institutions during the first two years after the effective date of the implementing regulations to obtain their estimates of time to repay. Rather, they are to call a telephone number established by the Federal Reserve (Public Law 109-8, paragraph $1301 a(11)(F)$ (ii)(I)). The Federal Reserve has no direct connection to the institutions' accounting systems for open end credit accounts. Likewise, customers of institutions regulated by the Federal Trade Commission (FTC) are to call an FTC telephone number for their estimates (paragraph 1301a(11)(G)). Again, this agency has no direct access to balance or other account information in creditors' accounting systems. From these provisions, it appears that the Congress did not contemplate a general method where creditors connect the Federal Reserve's required estimating table or formula directly to their accounting systems to supply the "estimates" of time to payoff.

Concerning the alternative of obtaining the necessary information from consumers who call, there will be some inconvenience for consumers in providing the necessary information over the telephone. They must consult their monthly disclosures to obtain the data, and they must enter the required information item by item into a touch-tone telephone or speak it 
over a voice-activated telephone response system. The amount of this inconvenience and the chance for errors likely rises with the number of necessary input items, a matter of some concern with modern credit card plans. In the past, single rates that applied to the entire balance were common, but today many credit card accounts have multiple annual percentage rates applying to multiple sub balances, as indicated previously: one rate for balances arising from purchases using the credit card, another rate for cash advance balances, and further rates that apply to balance transfer amounts, amounts from special promotions, introductory offers, etc.

Because of the potential complications that arise from any necessity for consumers to supply multiple rates and balances, some observers have proposed substituting a single rate and balance into the mathematical calculation instead of the actual multiple rates and balances of the actual account terms. The contention is that the error from applying a single rate to the whole balance is not so great that it destroys the advantages of this simpler approach, especially given the amount of error in the calculations arising from the necessity of employing a list of other assumptions anyway. Possibilities for a single rate include highest rate for any sub balance on the monthly statement and some sort of composite rate (weighted average or arithmetic average of actual rates). The composite rate approach would still require consumers to enter multiple rates into the telephone response system, but it would not require entry of associated multiple sub balances unless the composite rate were to be a weighted average based upon outstanding balances. In choosing the approach of having consumers provide the necessary information, a number of further issues arises:

First, if multiple rates and balances are used, there must also be a rule specifying how payments received are allocated between the various balances. One obvious possibility (mentioned earlier) is to adopt a revenue maximizing assumption and assume allocation of the entirety of payments received to the balance to which account with the lowest rate applies until that balance is 
paid in full. As the balances at the lower rate are repaid, interest accrues on higher rate balances until the rule allocates payments to them upon full repayment of the low rate balances and interest. This is the approach used in the computer program that produces the simulations in the tables.

Second, as mentioned, using any single rate and balance in lieu of contractual multiple rates and balances produces varying degrees of inaccuracy to the calculation and the resulting disclosures. To explore degree of inaccuracy through additional simulation, Table 2 shows calculated time to payoff employing the same hypothetical $\$ 3000$ and $\$ 7000$ balances of Table 1 but using alternative approaches to allocation of rates and balances. Each of the allocation alternatives in Table 2 compares time to payoff to the single-rate benchmark of Table 1 , first for the 2 percent payment rule and then the OCC payment rule sections of Table 1 (Parts 1 and 3 of Table 1 , respectively).

The initial alternative in each of the two subsections in Table 2 (line 1 ) splits the $\$ 3000$ balance into two components; the time to payoff is calculated after assigning the largest portion of the balance to the lower percentage rate. Line 6 does the same for the $\$ 7000$ balance. Subsequent lines of the table (lines 2-3 and then 7-8) make the same calculation but using the weighted average and arithmetic average interest rates, applied in each case to the total balances. The final two lines in each of the subsections of the table (lines 4-5 and 9-10) reverse the procedure and make the same calculations but assign the larger component of the balance to the higher percentage rate and the smaller component to the lower rate. (There is no need to repeat the line for the arithmetic average of the percentage rates, which remains the same).

Not surprisingly, time to payoff is the same or shorter if two rates are assigned to balance components than if the full balance compounds solely at the higher rate (compare lines 1 and 4 of Table 2 to benchmark \#1 and lines 6 and 9 to benchmark \#3). The reverse is true if the comparison is to the lower of the single rates (comparisons to benchmarks \#2 and \#4, respectively). 
Use of composite rates (the other lines of Table 2) also produces intermediate outcomes, closer to or farther from the upper and lower benchmark bounds according to the distribution of the balances and weighting of the rates. It is clear that while the choice ultimately involves the tradeoff between consumer convenience and varying degrees of mathematical accuracy, the differences are not so large as to be "out of the ballpark."

Third, if consumers are to enter sub balances as opposed to the whole outstanding balance on their accounts, then a further difficulty arises in that the appropriate sub balances for the calculations are currently not available on many standard monthly billing statements. The balance required for calculating time to payoff is the current ending sub balance. But under current Truth in Lending rules these sub balances are not required disclosures and they sometimes may be difficult to approximate from current disclosures.

Under the current regulatory structure, required sub balance disclosures on billing statements for open end accounts are the balances to which periodic rates apply for purposes of calculating a finance charge. "Under the common average daily balance method of balance calculation, these balances are the average daily balances and not the ending balances needed in the formula used to calculate time to payoff. In many situations average balance and ending balance will be similar (months in which there is little or no account activity except a minimum payment, months where the account activity is small relative to balance outstanding, or when most activity occurs early in the month, for example), and some account issuers voluntarily disclose both on their monthly statements, but in other cases they will diverge sharply and they are not separately disclosed. Specifically, average daily balance will diverge sharply from ending balance in any month when a large transaction occurs (credit advance or payment) near the end of the billing cycle. Since such months are likely to be disproportionately months in

${ }^{4}$ Federal Reserve Regulation Z, paragraph 226.7(e), 12 CFR, 226.7(e). 
which consumers call the disclosed telephone number for an estimate of time to payoff, this can introduce a substantial amount of error to the telephone disclosures made, regardless of the assumptions made in other areas. An approach of requiring each creditor newly to disclose ending sub balances by category may increase the accuracy of an inaccurate calculation somewhat for some consumers who call, but at the expense of requiring the necessary system changes to produce this outcome for all account holders who potentially might call, including those who do not do so.

Fourth, there will need to be some mechanism to insure that the consumer does not quote some short-term or temporary rate such as a preliminary "teaser" rate to induce opening an account but which will automatically change to a higher rate within some reasonably short period of time. If the caller reports a teaser rate rather than the "go to" rate, the estimate of time to payoff could be biased downward, possible sharply depending upon the difference between the teaser rate and its replacement.

2) Sources of information on minimum payment sizes. It seems it is necessary to assume some rule or another for calculating the required minimum payment rather than relying upon input from consumers by telephone. Accepting information from consumers could lead to further inaccuracy for two reasons: 1) the amount of the current minimum required payment on consumers' monthly statements reflects in most cases a percentage of the current balance, which declines over time reducing the required payment a decline not reflected in the current required minimum payment amount; and 2) the current required minimum payment may include late charges and other fees that are not recurring, or are at least are independent of the contractual minimum payment not due to fees. Consumer misstatements of contractual minimum payments arising from these sources could lead to substantial underestimates of the time to payoff, as shown by comparing the two sections of Table 3 to the first two parts of Table 1.

The sections of Table 3 and the first two parts of Table 1 are alike except that Table 1 uses alternatively the 2 percent 
rule and the OCC rule for calculating the required minimum payment and Table 3 uses the payments calculated by the two rules for the first month as the minimum payment consistently, month after month. Consumers themselves may well mentally approach the minimum payment issue the latter way, believing that the time to payoff should reflect the constant amount required by the current monthly statement, although it does not appear that this is the assumption contemplated by the new disclosure law. The table shows that estimated time to payoff is considerably shorter if the payment amount calculated by the formulas for the first month is used consistently.

The potential error produced by consistently using the dollar amount of the first payment to estimate time to payoff would be compounded if the dollar amount were to include any current fees like late charge or over-limit charges. The statutory assumptions imply that minimum payments arrive each month and so they also imply no future late charges. By the same assumptions, there is no future use of the account and so the balance will eventually fall below the contractual maximum, even if it exceeds this limit today and over limit charges apply this month or for some time into the future. But if such fees are addons to contractual minimum payment required then they should not be included in the calculation of time to payoff otherwise under the contract. Including them in a dollar amount used as a minimum payment formula proxy would systematically further bias the time estimate downward, sharply in many cases.

"Actual" number of months to payoff.

The alternative disclosure approach of paragraph 1301a(11) (J) concerning disclosure of the "actual" number of months to payoff rather than an "estimate" raises a variety of additional technical and policy issues. ${ }^{5}$ The statute does not define either term or specify the differences between them,

${ }^{5}$ Again, the discussion here does not purport to be or represent the Federal Reserve's legal or regulatory analysis of these matters. 
apparently leaving those responsibilities to the Federal Reserve. Presumably the kinds of calculations discussed to this point and maybe some others could serve in producing "estimates" of time to payoff, but as a technical matter the term "actual" is potentially much more problematic. It seems the definition would have to be forward looking based on information available to the disclosing creditor at the time of the disclosure and not subject to post hoc disputes at a later time when all information were known, for example interest rates in the intervening period. These and other legal matters are undecided at present and await further consideration.

As a policy matter, it seems the "actual" number of months would be preferable to an "estimate" and disclosure should be encouraged. A possible distinction between actual and estimate mentioned above concerns the degree to which the initial conditions for the calculation derive from the creditor's information system rather than from a telephoning consumer. For "actual" months a telephoning consumer might connect somehow directly to the creditor's accounting system, say through its customer service department's call center. The system could provide telephoning consumers with the calculated actual number of months to payoff using the set of, or some acceptable subset of, the current account balances from the consumer's account records, actual rates that currently apply to these balances, and actual current compounding methods and minimum payment formulas for that consumer's account, rather than relying on assumptions in these latter areas.

The statute itself offers encouragement for the "actual" months disclosure, in that it loosens the requirement that new disclosures occupy space on the front page of billing statements. Before creditors would avail themselves of this possibility there would still need to be clear answers to some additional questions:

First, they would need clear guidance on the correct formula to apply. Presumably this would be the same formula used for "estimates," but clarification would be necessary. 
Second, there would need to be some decisions on what represents accuracy of timing. Because not all credit files are instantaneously updated as purchases are made or payments received, there would need to be guidance on what balance outstanding is appropriate and permissible for the calculation of time to payoff. For verification a creditor's telephone voice response system could state to the consumer the balance upon which the calculation of time to payoff is based, but only as of some particular time. Choice of cut-off time, such as midnight the day before, two days before, a week before, the end of the previous billing cycle, or some other time might in some cases substantially impact the "actual" months disclosed, but some choice would be necessary.

Third, a creditor using an "actual" approach for one class of accounts or in one or more of its subsidiaries would need to be assured that using an "estimate" approach for other accounts or other subsidiaries does not somehow place it in violation when the responses from the two permissible, but different, systems offer different responses.

Fourth, creditors using this option would have to be assured that some assumptions required under the "estimate" method are still permissible (no late charges, over limit fees, or grace periods apply, assumed timing rules are the same, etc.).

Fifth, there would need to be assurance on a host of potential legal issues. For example, creditors would need to be assured that their adherence to a reasonable security system does not inadvertently put them into violation of Truth in Lending. For example, a creditor that requires in good faith an account number and password before connecting a consumer to the system should not be penalized or sued for a violation if the consumer is unable or unwilling to enter the password.

Even with assurance on these points, it seems that creditors likely will be concerned over comparisons showing that the same sets of facts do not produce the same results at different creditors. It seems that lack of congruity between the Federal 
Reserve/FTC system and those of creditors that provide "estimates" will be an issue of discussion.

Consumers' Account Use Behavior

Beyond the myriad other difficulties with underlying assumptions and information sources for initial conditions, there is still the question how often the statutory assumptions reflect actual credit card account use behavior. Available evidence suggests that only relatively few consumers use their accounts in a manner consistent with the statutory assumptions (only required minimum payments and no further use of the card while making minimum payments). This raises the question how often the required disclosures will reflect an accurate representation of a consumer's circumstances, even if the other calculating assumptions and information on other original conditions are reasonable.

1) Surveys of Consumers. Previously, information on accuracy of the core statutory assumptions has only been available from consumer surveys. To learn more about minimum payment behavior, questioning on these subjects, sponsored first by the Federal Reserve and later by the Credit Research Center, was included in the monthly Surveys of Consumers undertaken by the Survey Research Center of the University of Michigan. Interviewing on these issues took place in the summer of 1999 and the following January. In all, 2,000 consumers were questioned. ${ }^{6}$

The surveys found that just over one-third (35 percent) of holders of bank type credit cards with a revolving feature said they hardly ever pay their balance in full. When asked for more detail about the payment sizes they actually made, 7 percent said they hardly ever pay more than the minimum and another 9 percent of cardholders reported that they only sometimes pay more than the minimum amount due, for a total of 16 percent reporting they pay the minimum amount at least more than infrequently.

${ }^{6}$ See Thomas A. Durkin, "Credit Cards: Use and Consumer Attitudes, 1970-2000," Federal Reserve Bulletin, September, 2000, discussion on pp. 633-4. 
As discussed earlier, the new disclosure of time to payoff would only be accurate for card users who regularly pay the minimum each month and then do not make additional charges on their cards, regardless of the other calculating assumptions or sources of information on other initial conditions. From the consumer surveys, cross tabulating minimum payers against those who responded to another question that they stop using the card when making minimum payments found only about 4 percent of bank type card holders fall jointly into both groups. Thus, based on consumer survey evidence, it appears that the proposed new disclosure would be reasonably accurate for only a very small proportion of holders of bank type credit cards, even if the other assumptions and initial conditions were appropriate.

2) Sample of Credit Card Accounts. Beyond the consumer surveys, specific information on consumers' payment patterns has heretofore been available only to the creditors who issue the cards. They are able to review their own credit files to ascertain the patterns of card use and repayment, but even they do not have access to account information of their competitors and such information has been mostly unavailable to outside analysts.

Fortunately for the illustrative purposes here, a number of large credit card banks made available a sample of account information to the Credit Research Center for studying just such questions. Overall, they provided twelve month account histories for more than 300,000 randomly selected credit card accounts during the year 2001. Originally the data on individual credit card accounts were collected in three parts: a sample of card accounts from college-student marketing campaigns, another sample of accounts of young adults but not from a college marketing program, and a larger sample of more typical accounts not from a college program and not exclusively young adults. ' Appropriate weighting of the data according to frequency of each kind of

\footnotetext{
${ }^{7}$ See John M. Barron and Michael E. Staten, "Usage of Credit Cards Received Through College Student Marketing Programs," Journal of Student Financial Aid, Vol. 32, No. 3, 2004 .
} 
account in the underlying population of accounts permits construction and examination of a data set believed to be representative of the relatively new card accounts of five very large issuers of bank type credit cards. Because of their large size (all were in the top fifteen card issuers by volume of managed credit card receivables at the time of the sample), there is every reason to believe that this data set is also representative of the account experience of card issuers generally. Even if not perfectly representative of the universe of card accounts, the data set is large enough and representative enough to provide interesting descriptions of the card-use behavior of millions of consumers at the micro level. The appendix to this paper contains some more details about the data set and the sample-selection process.

To answer precisely questions about making contractually minimum payments, it would be necessary to know the identity of the card issuers and their policies for the specific accounts of individual card holders, but neither is available. Nonetheless, it is possible to define some amount as approximately a minimum allowable payment and to examine frequencies of behaviors under this definition. For example, if paying 5 percent or less of the balance is defined as making approximately the minimum monthly payment allowable, then about 37 percent of accounts made the minimum payment in the second month of the twelve month data set (Table 4, line 4).

A finding that about two-fifths of account holders making the minimum payment in a particular month does not mean that they always make minimum payments, however. Using more months of data, it appears that most of the minimum payers in the initial month considered do not always make minimum payments going forward. Notably, a bit under one-third of minimum payers in the initial month continue to make minimum payments for another six months after the initial month, while the others at least sometimes paid more than the minimum although not necessarily paying in full (see notes to line 4 in the table). This means then that only about 12 percent of accounts paid only the minimum for each of 
the seven months investigated (line 4A of Table 4). This proportion is much like the findings from the consumer surveys where 7 percent said they hardly ever pay more than the minimum and an additional 9 percent of cardholders reported that they pay more than the minimum amount due sometimes, for a total of 16 percent reporting they pay more than the minimum amount only sometimes or hardly ever.

The credit card data base further shows the reasonableness of the findings from the consumer surveys that only very few account holders make the minimum payment consistently and also do not use their card further. If those who pay the minimum for seven straight months are defined as hardly ever paying more than the minimum and then their accounts are examined further to see whether they continue to use their cards, then only about 4 percent of accounts in the credit card data base fall into the joint category of making only minimum payments and not further using the card (data not in a table). This is precisely the same as the measurement from the consumer surveys, one measure from account holders and the other from account issuers. This degree of inaccuracy on the statutory assumptions necessary for calculating time to payoff on credit card accounts does not argue that the new required disclosure is going to be strictly accurate in very many cases, even apart from issues surrounding the other assumptions required for the calculations.

The credit card data base also permits exploration of the frequency of accurate and inaccurate disclosures of time to payoff under less strict definitions of accuracy. Notably, using the credit card data base it is possible to construct a set of disclosures that would be required under some set of assumptions about rates and payments and then to calculate how accurate the disclosures turned out to be based upon consumers' actual carduse behavior during some time period. This approach can even employ a variety of different definitions of accuracy.

Suppose that the annual percentage rate of finance charge on revolved card accounts reflects the statutory example: APR of 17 percent and minimum payment requirement of 2 percent of the 
balance outstanding or $\$ 20$, whichever is greater, or the full amount owed if less than $\$ 20$. Under this (or some other) set of assumptions it is possible to calculate a set of account payment durations. Then, following passage of a month or some other time period, it is possible to calculate another set of payment durations based upon the account balance at that time and then to compare the two sets of calculations. The percentage by which the second calculation differs from the initial one (the original required disclosure) could then be defined as the percentage inaccuracy of the initial disclosure over the time period. In similar manner percentage errors of this sort could be constructed for a variety of time periods. Each could be compared to the initial required disclosures according to some standard of accuracy. This would then make each initial disclosure either "accurate" or "inaccurate" according to the chosen standard for the given time period.

For example, the credit card data base was used to prepare an initial estimate of time to payoff for each card account under the assumptions listed above: 17 percent APR and minimum payment of 2 percent of the outstanding balance or $\$ 20$, whichever is greater, or the full account balance if less than $\$ 20$. Then the same calculation was undertaken after one month and the two calculations compared under an accuracy standard of not differing by more than 10 percent in month 2 from the initial disclosure required at month one.

Undertaking such an exercise shows that consumers' intervening actual use of their credit card accounts frequently renders such a payoff disclosure inaccurate (often very inaccurate) under such a standard, even over as short a time interval as one month. Using the 10 percent divergence criterion of accuracy, only about half of initial month disclosures remain accurate one month later, not an especially promising outcome, and the degree of accuracy continues to decline sharply thereafter (Table 5). After six months, only about a quarter of the initial disclosures remain accurate under this criterion. Furthermore, the magnitudes of the percentage errors increase as 
well. After six months, about half of the initial disclosures are off by more than 50 percent (that is, a new disclosure would add or subtract 50 percent to or from the original duration). With a finding of this sort, it seems difficult to argue strongly that the initial account-specific disclosure would be more useful than a simple generic reminder that constantly paying the minimum could lead to a long repayment period.

Even this dismal accuracy finding may be more optimistic than the facts warrant. It is possible that some cases deemed accurate actually are counted as such by coincidence rather than by fact. For instance, an account whose initial disclosure is still deemed accurate at the six months point may receive this designation because its balance outstanding is similar at that time to the initial balance, but the balance could have varied dramatically (and, therefore, the accuracy of the initial disclosure varied widely as well) within the time interval. Thus, in such cases it seems a final designation as "accurate" seems more coincidental that actual.

To explore this possibility, calculations were made on another definition of accuracy that eliminated the chance of "accuracy" in a later month only by coincidence. This second standard of accuracy requires that the original disclosure be accurate within 10 percent throughout the whole time period. Thus, disclosure on an account that is off by more than 10 percent one month later is counted as inaccurate, even if by coincidence it should again become counted as "accurate" in some later month.

By this definition of accuracy, the approach of an initial payment duration disclosure appears mostly unpromising. This second definition of accuracy reveals that only about 18 percent of initial disclosures are accurate after six months (Table 6). The proportion deemed accurate also varies sharply by account use behavior. Not surprisingly, almost no convenience users receive disclosures that are still accurate after passage of six months. This comes about, of course, because of the nature of accounts used largely for the purpose of making payments rather than as a 
credit source and the account balances can fluctuate substantially by month. In contrast, about half of minimum payers, about 6 percent of card accounts, receive an initial disclosure defined as still accurate after six months. This proportion also is very consistent with the 4 percent of card holders identified in the consumer surveys as minimum payers and not further using their cards when they pay the minimum amount.

\section{Conclusion}

An amendment to the Truth in Lending Act contained in the Bankruptcy Abuse Prevention and Consumer Protection Act of 2005 requires that creditors provide to consumers on all open end credit accounts a warning label, an example, and a telephone number to request further information about time to pay off the account if making only minimum payments month after month. Providing the newly required disclosures that represent conditions over an unknown future will necessitate a variety of calculating assumptions and a source of information on outstanding credit balances in consumers' accounts. The estimates of time to payoff required are sensitive to both the underlying calculating assumptions and to information on account balances. For this reason, the new statutory requirement provides significant challenges in making the necessary adjustments to Regulation $\mathrm{Z}$ to implement the statutory amendment in a manner most likely to provide meaningful benefit to consumers. 
Table 1

Number of Months to Payoff of Open End Credit Accounts Under Various Assumptions About Account Terms

Part 1: 2\% of Balance Minimum Payment Rule ${ }^{1}$

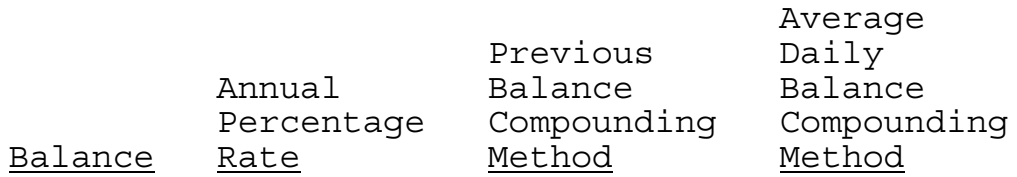

$\begin{array}{llll}\$ 1000 & 17 \% & 88^{*} & 89 \\ \$ 1000 & 12 \% & 70 & 70 \\ \$ 1000 & 8.99 \% & 63 & 63 \\ & & & \\ \$ 3000 & 17 \% & 276 & 280 \\ \$ 3000 & 12 \% & 179 & 180 \\ \$ 3000 & 8.99 \% & 151 & 151 \\ & & & \\ \$ 7000 & 17 \% & 264 & 427 \\ \$ 7000 & 12 \% & 218 & 265 \\ \$ 7000 & 8.99 \% & & \end{array}$

Part 2: Accrued Finance Charges Plus 1\% of Balance Minimum Payment Rule

\begin{tabular}{|c|c|c|c|}
\hline Balance & $\begin{array}{l}\text { Annual } \\
\text { Percentage } \\
\text { Rate }\end{array}$ & $\begin{array}{l}\text { Previous } \\
\text { Balance } \\
\text { Compounding } \\
\text { Method }\end{array}$ & $\begin{array}{l}\text { Daily } \\
\text { Balar } \\
\text { Compc } \\
\text { Methe }\end{array}$ \\
\hline$\$ 1000$ & $17 \%$ & 82 & 82 \\
\hline$\$ 1000$ & $12 \%$ & 70 & 70 \\
\hline$\$ 1000$ & $8.99 \%$ & 63 & 63 \\
\hline$\$ 3000$ & $17 \%$ & 191 & 192 \\
\hline$\$ 3000$ & $12 \%$ & 179 & 180 \\
\hline$\$ 3000$ & $8.99 \%$ & 171 & 171 \\
\hline$\$ 7000$ & $17 \%$ & 276 & 27 \\
\hline$\$ 7000$ & $12 \%$ & 264 & 26 \\
\hline$\$ 7000$ & $8.99 \%$ & 256 & 25 \\
\hline
\end{tabular}


Table 1 continued

Part 3: 4\% of Balance Minimum Payment Rule ${ }^{3}$

\begin{tabular}{|c|c|c|c|}
\hline & $\begin{array}{l}\text { Annual } \\
\text { Percentage } \\
\text { Rate }\end{array}$ & $\begin{array}{l}\text { Previous } \\
\text { Balance } \\
\text { Compounding }\end{array}$ & $\begin{array}{l}\text { Average } \\
\text { Daily } \\
\text { Balance } \\
\text { Compounding } \\
\text { Method }\end{array}$ \\
\hline Balance & Rate & $\underline{\text { Method }}$ & Method \\
\hline$\$ 1000$ & $17 \%$ & 58 & 58 \\
\hline$\$ 1000$ & $12 \%$ & 52 & 52 \\
\hline$\$ 1000$ & $8.99 \%$ & 49 & 49 \\
\hline$\$ 3000$ & $17 \%$ & 100 & 100 \\
\hline$\$ 3000$ & $12 \%$ & 88 & 88 \\
\hline$\$ 3000$ & $8.99 \%$ & 82 & 83 \\
\hline$\$ 7000$ & $17 \%$ & 132 & 133 \\
\hline$\$ 7000$ & $12 \%$ & 116 & 116 \\
\hline$\$ 7000$ & $8.99 \%$ & 108 & 108 \\
\hline
\end{tabular}

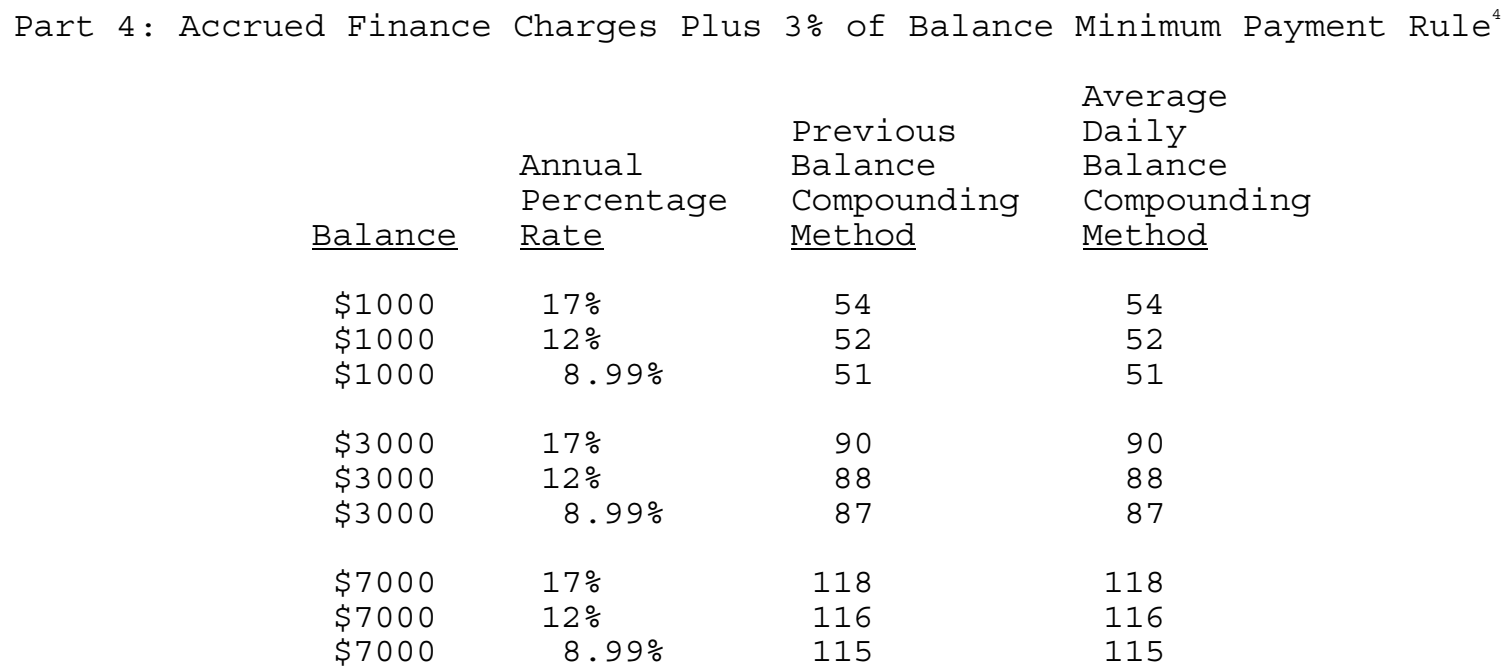

Notes:

${ }^{1} 2 \%$ of the outstanding balance or $\$ 20$, whichever is greater, or the full balance if less than $\$ 20$.

2 All accrued finance charges and $1 \%$ of the balance or $\$ 20$, whichever is greater, or the full balance if less than $\$ 20$.

$34 \%$ of the outstanding balance or $\$ 20$, whichever is greater, or the full balance if less than $\$ 20$.

${ }^{4}$ All accrued finance charges and $3 \%$ of the balance or $\$ 20$, whichever is greater, or the full balance if less than $\$ 20$.

* Assumptions in statutory example. 
Table 2

\section{Number of Months to Payoff of Open End Credit Accounts Under Various Assumptions About Account Terms Including That Two Percentage Rates Apply to Two Sub Balances}

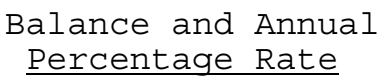

5. Total \$3000

@ Weighted average 14.33\%

Benchmark \#3 (from Table 1):

$\$ 7000 @ 17 \%$

Benchmark \#4 (from Table 1): $\$ 7000 @ 8.99 \%$

Alternatives:

6. Total \$7000 $\$ 1000 @ 17 \%$ $\$ 6000 @ 8.99 \%$

7. Total \$7000

@ Weighted average 10.13\%

8. Total \$7000

@ Arithmetic average 13\%

$\begin{array}{ll} & \text { Average } \\ \text { Previous } & \text { Daily } \\ \text { Balance } & \text { Balance } \\ \text { Compounding } & \text { Compounding } \\ \text { Method } & \text { Method }\end{array}$

276

280

151

151

254

257

176

176

192

193

272

276

213

214

421

427

218

218

369

374

233

234

284

286 
Table 2 (Continued)

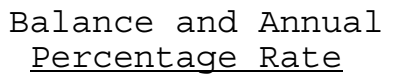

2. Total \$3000

@ Weighted average 11.66\%

3. Total \$3000

@ Arithmetic average 13\%

4. Total \$3000 $\$ 2000 @ 17 \%$ $\$ 1000 @ 8.99 \%$

5. Total $\$ 3000$

@ Weighted average 14.33\%

$\begin{array}{ll} & \text { Average } \\ \text { Previous } & \text { Daily } \\ \text { Balance } & \text { Balance } \\ \text { Compounding } & \text { Compounding } \\ \text { Method } & \text { Method }\end{array}$

420

426

369

373

$\begin{array}{ll} & \text { Average } \\ \text { Previous } & \text { Daily } \\ \text { Balance } & \text { Balance } \\ \text { Compounding } & \text { Compounding } \\ \text { Method } & \text { Method }\end{array}$

191

192

171

171

191

192

179

179

182

182

191

192

185

185 
Table 2 (Continued)

\section{Balance and Annual \\ Percentage Rate}

$\begin{array}{ll} & \text { Average } \\ \text { Previous } & \text { Daily } \\ \text { Balance } & \text { Balance } \\ \text { Compounding } & \text { Compounding } \\ \text { Method } & \text { Method }\end{array}$

276

276

256

256

276

276 $\$ 1000 @ 17 \%$ $\$ 6000 @ 8.99 \%$

7. Total \$7000

@ Weighted average 10.13\%

8. Total $\$ 7000$

@ Arithmetic average 13\%

9. Total $\$ 7000$ $\$ 6000 @ 17 \%$ $\$ 1000 @ 8.99 \%$

10. Total $\$ 7000$

@ Weighted average 15.86\%
259

259

266

266

276

276

273

273

Notes:

$12 \%$ of the outstanding balance or $\$ 20$, whichever is greater, or the full balance if less than $\$ 20$.

2 All accrued finance charges and $1 \%$ of the balance or $\$ 20$, whichever is greater, or the full balance if less than $\$ 20$. 
Table 3

Minimum Payment Remains Constant at Amount of First-Month Payment

Part 1: 2\% of Balance Minimum Payment Rule

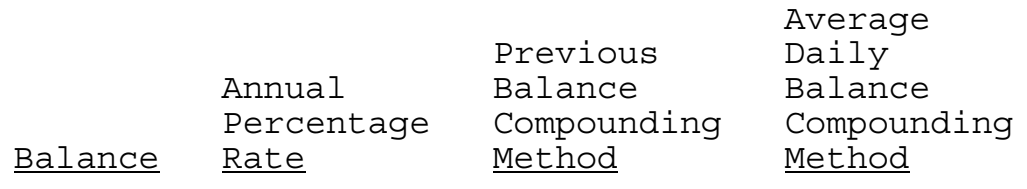

$\begin{array}{llll}\$ 1000 & 17 \% & 88^{*} & 89 \\ \$ 1000 & 12 \% & 70 & 70 \\ \$ 1000 & 8.99 \% & 63 & 63 \\ & & & \\ \$ 3000 & 17 \% & 88 & 89 \\ \$ 3000 & 12 \% & 63 & 63 \\ \$ 3000 & 8.99 \% & 88 & 89 \\ \$ 7000 & 17 \% & 70 & 70 \\ \$ 7000 & 12 \% & 63 & 63 \\ \$ 7000 & 8.99 \% & & \end{array}$

Part 2: Accrued Finance Charges Plus 1\% of Balance Minimum Payment Rule

\begin{tabular}{|c|c|c|c|}
\hline & & & Average \\
\hline & & Previous & Daily \\
\hline & Annual & Balance & Balance \\
\hline & Percentage & Compounding & Compounding \\
\hline Balance & Rate & Method & Method \\
\hline
\end{tabular}

$\begin{array}{llll}\$ 1000 & 17 \% & 63 & 63 \\ \$ 1000 & 12 \% & 70 & 70 \\ \$ 1000 & 8.99 \% & 63 & 63 \\ \$ 3000 & 17 \% & 63 & 63 \\ \$ 3000 & 12 \% & 70 & 70 \\ \$ 3000 & 8.99 \% & 75 & 75 \\ \$ 7000 & 17 \% & 63 & 63 \\ \$ 7000 & 12 \% & 70 & 70 \\ \$ 7000 & 8.99 \% & 75 & 75\end{array}$

Notes :

Assumptions in statutory example. 
Table 4

Payment of Account Balances on Credit Card Accounts (Percent of Active Accounts)

Payment experience in month:

1) No balance in month

2) Paid approximately in full (90\% or more)

3) Paid more than minimum, but less than in full

(paid more than 5\%, but less than 90\%)

Notes for line 3:

A) Paid more than 5\% but less than $10 \%$

B) Paid more than $10 \%$ but less than $50 \%$

C) Paid more than 50\% but less than $90 \%$

4) Paid approximately the minimum amount

(paid less than 5\%)

Notes for line 4 :

A) And then paid approximately the minimum for the following six months

B) And then paid off account at least once during the following six months

C) And exhibited all other payoff behaviors during the following six months
Percent

16.3

20.3

26.4

8.8

13.9

3.6

37.0

11.9

10.1

15.0

100.0

Total

Notes:

Components may not sum to totals because of rounding.

Source: Credit Research Center credit card data base. 
Table 5

Potential Errors on Payment Duration Disclosure Arising From Assuming That Minimum Payment is Always Made

Instead of Using Actual Historical Account Behavior Experience (Percent of Active Accounts)

\section{Accuracy of Initial Disclosure:}

1. Accurate (Within \pm 10 Percent)

2. Inaccurate (Error $> \pm 10$ Percent)

Total

Note:

2A. Very inaccurate (Error > +25 percent)

2B. Highly inaccurate (Error > \pm 50 percent)
After one month

51.0

49.0

100.0

37.2

27.8

41.3

After

three

months

36.1

63.9

100.0

52.2

61.6

50.7

Notes :

Components may not sum to 100 because of rounding.

Source. Credit Research Center credit card data base. 
Table 6

Accuracy of Initial Disclosures of Payment Duration Throughout a Six Month Period

Based Upon Payment Behavior of Account Holders (Percent of Active Accounts Within Account Categories)

\begin{tabular}{|c|c|c|c|c|c|c|}
\hline $\begin{array}{l}\text { Accuracy of Initial } \\
\text { Disclosure }\end{array}$ & $\begin{array}{l}\text { Pure } \\
\text { Conven- } \\
\text { ience } \\
\text { users }\end{array}$ & $\begin{array}{l}\text { Conven- } \\
\text { ience } \\
\text { users }\end{array}$ & Payers & $\begin{array}{l}\text { Fluctu- } \\
\text { ators }\end{array}$ & $\begin{array}{l}\text { Minimum } \\
\text { payers }\end{array}$ & All \\
\hline $\begin{array}{l}\text { 1. Accurate } \\
\quad(\text { Within } \pm 10 \text { Percent })\end{array}$ & 3.1 & 0.4 & 3.0 & 18.9 & 58.1 & 17.8 \\
\hline $\begin{array}{l}\text { 2. Inaccurate } \\
(\text { Error }> \pm 10 \text { Percent })\end{array}$ & 96.9 & 99.6 & 97.0 & 81.1 & 41.9 & 82.2 \\
\hline Total & 100.0 & 100.0 & 100.0 & 100.0 & 100.0 & 100.0 \\
\hline
\end{tabular}

Notes:

"Pure convenience users" are those who pay accounts in full at least five times in seven months.

"Convenience users" are those who pay account in full three or four times in seven months.

"Payers" are those who pay account in full one or two times in seven months.

"Fluctuators" are those who at least sometimes pay more than 5 percent of their balance but do not pay the balance in full in seven months.

"Minimum payers" are those who pay 5 percent or less each month over seven months.

Source. Credit Research Center credit card data base. 


\section{APPENDIX: SAMPLE OF CREDIT CARD ACCOUNTS}

To examine aspects of account use behavior, a large pooled random sample of card accounts was assembled in 2001 from the portfolios of five of the fifteen largest credit card issuers at the end of 2000 , ranked by managed card receivables. The random selection was done in such a way as to be representative of the relatively new card accounts of the issuer. Together, these accounts likely are quite representative of the universe of domestic new card accounts overall, largely because of the size of the issuers. Accounts selected were restricted to those less than three years old at the beginning of the observation period.

Data from each account is a record of 12-14 months of account activity for each of the approximately 336,000 selected accounts for a total of close to 4.5 million monthly observations. ${ }^{1}$ These monthly observations included accounts open from one to forty-one months. However, the different sampling frameworks adopted by the various companies resulted in some differences in the distribution of accounts by account age (months since initial opening), as well as the initial month and subsequent duration of the observation period. To obtain a more uniform data set for analysis, the observation period for each account was restricted to the first twelve months of monthly statement data provided by each issuer. The sample was further restricted to accounts that had been open for thirty-two or fewer months as of the end of the observation period for each account. Thus, the final data set contains accounts open from one to twenty-one months at the beginning of the observation period and for most of which twelve months of subsequent account information is available. Some accounts in the restricted sample have fewer than twelve months in the observation period because they charge off or close.

${ }^{1}$ For a fuller description of the data collection see John M. Barron and Michael E. Staten, "College Student Credit Card Usage," Georgetown University Credit Research Center Working Paper Number 65, 2002. As described there, the data set collected had three components representing accounts as part of the card issuers' college student marketing programs, accounts opened by other young adults, and accounts held by older individuals. For the analysis reported here these components were appropriately weighted so the weighted sample is representative of the age distribution of each issuer's overall portfolio. 
Weights were constructed to reflect the relative size of each issuer's portfolio in the pooled group. Due to varying intervals over which the accounts were sampled across the five companies and different levels of specificity across companies in reporting the underlying population from the different categories of accounts, it was not possible to construct statistically ideal weights. Nonetheless, the weights used can be considered to provide a data base of the twelve-month experience of over 300,000 accounts that were opened at major credit card issuers during the period from mid-1998 through early 2000 and were active during 2000-2001. The restricted sample contains approximately 316,000 accounts with about 3.8 million monthly observations.

All analyses exclude inactive or "dormant" accounts, that is, accounts with no charge activity, payment, positive balance, or some other posting of activity at some point during the observation period. Dormant or inactive accounts may reflect a credit card being held in reserve by the individual for an emergency or a credit card that has been discarded or destroyed by the holder without notifying the issuer.

For analysis the following variables were available:

Current balance

Credit line

Payment made

Monthly fees

Finance charges

Cash advances

Delinquency status (30 days, 90 days)

Holder's birth date

Date opened

FICO score

Availability of these variables permitted calculation of the following additional variables:

Utilization rate

Proportion with a positive balance

Proportion with a cash advance

Monthly charge activity 
Proportion paying in full each month

Proportion of dollars delinquent 90 days

Age of account (months)

Age of holder

And others 